\title{
Z HISTORII BADAŃ TRASEOLOGICZNYCH W POLSKIEJ ARCHEOLOGII EPOKI KAMIENIA
}

\section{ON HISTORY OF TRASEOLOGY IN THE POLISH STONE AGE ARCHAEOLOGY}

\author{
Jolanta Małecka-Kukawka \\ Instytut Archeologii, Uniwersytet Mikołaja Kopernika \\ ul. Szosa Bydgoska 44/48, 87-100 Toruń, Poland
}

ABSTRACT. The paper is an outline of history of the tool function studies in the Polish Stone Age archaeology. An experimental-traseological method of the Russian scholar S.A. Semenov has been known in archaeology for about forty years. This microscopic method of tool function identification has soon become one of the most important methods of archaeological data analysis from the oldest phases of prehistory. The paper discusses reasons of a poor reception of traseology in Poland. This lack of reflection on tool function is linked to a dominant culture-historical paradigm in Stone Age archaeology.

\section{WPROWADZENIE}

Blisko pół wieku temu (1957) ukazała się książka S.A. Siemionowa Pierwobytnaja technika. Jak pokazała historia archeologii, książka ta stała się dziełem przełomowym w zakresie „badania najstarszych narzędzi i wytworów na podstawie śladów pracy” (swobodne thumaczenie podtytułu książki Siemionowa). Jednak rzeczywisty rozgłos i autentyczną karierę w nauce metoda Siemionowa zyskała po 1964 r., kiedy ukazała się anglojęzyczna wersja jego pracy. W roku 2004 minęło 40 lat istnienia traseologii w światowej archeologii. Szkic mój nie powstał jednak z chęci uświęcenia tego jubileuszu. Czterdzieści czy czterdzieści siedem lat to czas wystarczająco długi, by spojrzeć z dystansem na obecność i rozwój badań traseologicznych w polskiej archeologii z próbą oceny, dlaczego w Polsce analiza funkcjonalna nie stała się pełnoprawną metodą wchodzącą w zakres studiów nad epoką kamienia, na równi $z$ analizą typologiczną czy surowcową.

Na temat historii rozwoju traseologii powstało wiele prac ${ }^{1}$. Nie historia samej metody jest celem tego artykułu, lecz próba refleksji nad przyczynami słabej - w mojej ocenie

\footnotetext{
${ }^{1}$ Szerzej Cook, Dumont 1987, s. 53-61; Korobkowa 1999, s. 11-14; Małecka-Kukawka 2001, s. 9-12, 17-20.
} 
- recepcji traseologii w Polsce. Zdaję sobie sprawę, że podejmuję się zadania trudnego, ocena takiego a nie innego stanu rzeczy w nauce jest bowiem zawsze nacechowana subiektywnymi przekonaniami, z którymi nie wszyscy muszą się zgadzać. Ponieważ traseologia od początku lat dziewięćdziesiątych stała się jednym z obszarów moich poczynań badawczych, przeto sądzę, że ten przyczynek będzie pożyteczny dla czytelników zainteresowanych historią i rozwojem celów i metod badawczych w archeologii.

\section{POCZĄTKI}

Funkcje pradziejowych narzędzi krzemiennych i kamiennych, od momentu gdy zostaly właściwie zinterpretowane jako wytwory ludzkie, zawsze stanowiły przedmiot zainteresowania. Początki tych zainteresowań umieszczać należy w drugiej połowie XIX w., kiedy po raz pierwszy podjęto się funkcjonalnej interpretacji krzemiennych wytworów paleolitycznych, wykorzystując szerzej analogie etnograficzne ${ }^{2}$.

Kolejne dziesięciolecia to czas intensywnego rozwoju archeologii prehistorycznej, w tym także archeologii epoki kamienia ${ }^{3}$. Problem zastosowań narzędzi krzemiennych nie zniknął z pola badawczego prehistoryków, lecz brak właściwej metody określania funkcji mógł być zapewne ważną przyczyną, że w archeologii epoki kamienia naczelne miejsce zajęla (i zajmuje do dzisiaj) typologia. Jej znaczenie trafnie ujął A.J. Tomaszewski:

Kategorię zabytków kamiennych, wyjątkowo uprzywilejowaną w badaniach, zawsze stanowiły narzędzia, uznawane za docelowy punkt wytwórczości. W szczególności zaś na zróżnicowaniu w tej grupie wytworów koncentrowała się znaczna część wysiłków badawczych, które w ramach kulturowo-historycznej orientacji zmierzały do wyznaczania jednostek taksonomicznych mających znaczenie społeczno-kulturowe. [...] Paradygmat kulturowo-historyczny przyznał przy tym wyjątkowo ważne miejsce tym typom, które cechowała wysoka diagnostyczność w systematyce czasowo-przestrzennej zespołów. W konsekwencji na ujawnianiu takich typów zaangażowana była znaczna część badań, a niekiedy nawet wyobrażeń o celach archeologii".

Czy jednak wcześniejszy brak naukowej metody wiarygodnego określania funkcji narzędzi w trakcie rozwoju archeologii pradziejowej był jedynym powodem tego, że traseologia, kiedy już pojawila się w literaturze, nie rozwinęla się w polskim środowisku badaczy epoki kamienia? Uważam, że nie. Najpoważniejszą, wręcz fundamentalną przyczyną braku zainteresowania analizą funkcjonalną od czasu opublikowania jej podstaw metodycznych, jest - moim zdaniem - glęboko zakorzeniony sposób myślenia o celach badawczych prehistorii, ogólnie określany szkołą kulturowo-historyczną ${ }^{5}$. Ten kulturowo-historyczny paradygmat uprawiania archeologii, z wyraźnym

\footnotetext{
Szerzej Korobkowa 1999, s. 11-12.

${ }^{3}$ W Polsce Lech 1999, s. 39-42.

${ }^{4}$ T omaszewsk i 1988, s. 29-30.

${ }^{5}$ Ostatnio Mamzer 2004.s. 132-145.
} 
ukierunkowaniem na badanie etniczności, ukształtował się w prężnie rozwijającym się środowisku prehistoryków dwudziestolecia międzywojennego ${ }^{6}$. W latach powojennych przełom metodologiczny i reorientacja celów badawczych archeologii, w tym zaadoptowanie materializmu historycznego jako teorii, z uwagi na sytuację społeczno-polityczną był nieunikniony, choć nie dotyczyło to - co zrozumiałe - wszystkich archeologów ${ }^{7}$. Wielki program milenijny, związany $z$ badaniami nad początkami państwa polskiego, był zapewne jedną z przyczyn, że ów metodologiczny przewrót w niewielkim stopniu dotyczył znajdującej się wówczas „,w cieniu średniowiecza” archeologii najstarszych okresów pradziejów ${ }^{8}$. Dominacja „kultury archeologicznej” jako narzędzia badawczego, czy też szerzej - jako przedmiotu badań w polskiej archeologii powojennej ${ }^{9}$, miała niewątpliwy wpływ na to, że mikroskopowa metoda dostarczania informacji o funkcjach narzędzi nie znalazła miejsca $w$ badaniach nad epoką kamienia. Mam świadomość, że powyższe stwierdzenie jest dużym uproszczeniem, chcę jednak dalej wykazać, że właśnie ów kulturowo-historyczny paradygmat legł u źródel braku zainteresowania funkcjami narzędzi, przynajmniej do połowy lat siedemdziesiątych XX w. ${ }^{10}$

Traseologia jako metoda analityczna $w$ archeologii pojawiła się $\mathrm{i}$ upowszechniła w wielu krajach zachodnich Europy, w USA i Japonii wkrótce po publikacji pracy Siemionowa w $1964 \mathrm{r}$. W szybkim tempie zaczęły powstawać laboratoria, pojawiła się grupa badaczy, którzy z jednej strony rozpoczęli wdrażanie metody zaproponowanej przez Siemionowa, z drugiej - zaczęli prowadzić intensywne studia nad metodyką analizy funkcjonalnej oraz możliwościami jej twórczych zastosowań w archeologii (nie bacząc na jej marksistowski rodowód). Pojawiły się nowe specjalizacje (np. fitotraseologia), wprowadzono do badań nowy sprzęt - mikroskopy skaningowe, otwierające zupełnie nowe możliwości interpretacyjne dzięki zastosowaniu wielkich powiększeń. Ogromnym wkładem badaczy zachodnich w rozwój traseologii było przeprowadzenie „ślepych testów" - dwóch programów, mających na celu weryfikację wiarygodności oznaczeń mikroskopowych ${ }^{11}$. Naukowcy zajmujący się rozmaitymi aspektami analizy mikroskopowej, stworzyli prężne środowisko dyskusyjne, które poza indywidualnymi kontaktami, miało możliwość wymiany doświadezeń na organizowanych kongresach specjalistycznych $^{12}$. O intensywności rozwoju traseologii najlepiej mogą zaświadczyć pierwsze ujęcia o charakterze historiograficznym, które pojawiły się relatywnie szybko, już po kilkunastu latach istnienia traseologii13.

\footnotetext{
${ }^{6}$ A bramowicz 1991, s. 105-138; Lech 1999, 39-54.

${ }^{7}$ A bramowicz 1991, s. 146-162; Lech 1997, s. 210; 1999, s. 57-59, 84 91; T abaczyński 2000, s. $513-525$.

${ }^{8}$ Lech 1999, s. $65-78,110$

${ }^{9}$ Lech 2000 , s. $173-174$

${ }^{10}$ Lech 1999 , s. $110-115$.

${ }^{11}$ Unrath, Owen, van Gijn, Moss, Plisson, Vaughan 1986, s. 117-176; Małecka-Kukawk a 2001 , s. $27-28$

${ }^{12}$ Np. Hayden ed. 1979.

${ }^{13}$ Np. Cook, Dumont 1987; Jensen 1988.
} 
W Polsce książka Siemonowa miała szansę upowszechnienia się o kilka lat wcześniej, niż na Zachodzie. Z perspektywy kontekstu politycznego można byłoby sądzić, że nowa metoda, dotycząca narzędzi pracy, materialnej kategorii do badania sił wytwórczych, zrodzona w środowisku uczonych radzieckich, w przodującym wówczas ośrodku badań nad epoką kamienia - Instytucie Archeologii Rosyjskiej Akademii Nauk w Leningradzie - mogła i powinna trafić na żyzny grunt polskiej archeologii ${ }^{14}$. Tymczasem, śledząc wątpliwą karierę traseologii w Polsce, można stwierdzić, że zainteresowanie środkami pracy i wytwarzaniem ,mogło, ale na pewno nie zdążyło zaistnieć jako ulubiony temat archeologii »epoki stalinowskiej«"15. Dzieło Siemionowa opublikowane zostało już po epoce stalinowskiej (kilka jego artykułów związanych z traseologią ukazało się wcześniej), a sam autor dopiero po wydrukowaniu pracy w języku angielskim w 1964 r. oraz jej wznowieniach w 1972 i 1975 r. doczekał się uhonorowania swej twórczości naukowej przyznaniem mu Nagrody Państwowej ZSRR w 1975 r. $^{16}$

Pierwszym sygnałem o znajomości metody Siemionowa w środowisku polskich „krzemieniarzy” jest wypowiedź S.K. Kozłowskiego z 1968 r. na lamach ZOW:

Dziedziną dostarczającą szczególnej ilości nieporozumień jest sprawa stosunku formy narzędzi krzemiennych do ich faktycznych lub domniemanych funkcji. W naszej „fachowej” literaturze zbyt często spotykamy się z radosnym gaworzeniem na ten temat, natomiast zbyt rzadko znajdujemy rzetelną, przez co bardziej prozaiczna, interpretację. [...] jednak czegoś się z tych narzędzi krzemiennych można dowiedzieć - trzeba tylko w odpowiedni sposób je badać.

Pozostaje więc żmudna, ale jedyna metoda badań szczególowych, które już są prowadzone i dają wyniki często zaskakujące. Należy w tym miejscu wymienić m.in. badania eksperymentalne prowadzone przez S.A. Siemionowa. Droga drobiazgowych obserwacji pod mikroskopem bada on ślady pracy, jakie zachowały się na częściach pracujących narzędzi krzemiennych. Wyniki, choć mało romantyczne, są ciekawe i wielce pouczające ${ }^{17}$.

Ta wypowiedź przyszłego profesora archeologii, wybitnego badacza epoki kamienia mogła być sygnałem, że badania traseologiczne znajdą swe miejsce w studiach nad narzędziami krzemiennymi. Bliską refleksję, jeśli chodzi o uznanie ważności określania funkcji narzędzi krzemiennych znajdziemy w artykule kolejnej wybitnej postaci polskiej archeologii, J.K. Kozłowskiego z 1971 r. ${ }^{18}$ Jest ona tak znacząca dlatego, że opublikowana została w ważnych z perspektywy badań nad krzemieniarstwem młodszej epoki kamienia materiałach z konferencji w Nowej Hucie. Wśród zarysowanych wówczas kierunków badań znalazł się także postulat konieczności określenia stosunku typologii do funkcji wyrobów oraz pozamorfologicznych kryteriów klasyfikacji. Przez następne trzydzieści lat postulat ten nie został zrealizowany.

\footnotetext{
${ }^{14}$ Tak przynajmniej widzi to P. B arford w swej kontrowersyjnej pracy $\mathrm{z} 1995 \mathrm{r}$.

${ }^{15}$ Lech 1997, s. 199

${ }^{16}$ Korobkova, Ščlinskij 1996, s. 5

${ }^{17}$ K ozłowsk i S.K. 1968, s. 91-92.

${ }^{18}$ Kozlowski J.K. 1971, s. 139-146.
} 
Można się zastanawiać nad przyczynami tak późnej reakcji polskich archeologów na tę wartościową poznawczo metodę. Najlepiej zapewne odpowiedzieliby sami, cytowani wyżej autorzy. Być może przyczyną braku inwestycji w stworzenie laboratorium traseologicznego (m.in. spore koszty aparatury) było zdominowanie badań archeologicznych przez akcję milenijną?

\section{POWIEW PROCESUALIZMU}

Ożywienie zainteresowań badaniami traseologicznymi w polskiej archeologii przypada na lata siedemdziesiąte ubiegłego wieku ${ }^{19}$. Niewątpliwie stało się to za przyczyną rezygnacji z kulturowo-historycznego modelu uprawiania archeologii i zainteresowania badaniami procesów społecznych, gospodarczych czy ekologicznych wśród części ówczesnych prehistoryków ${ }^{20}$. Modelową monografią, wytyczającą nowe kierunki badawcze jest praca Późny mezolit. Próba wieloaspektowej analizy otwartych stanowisk piaskowych autorstwa R. Schilda, M. Marczak i H. Królik z 1975 r., gdzie znajdujemy następujące zdanie:

Intensywne i pracochłonne badania śladów użytkowania na narzędziach krzemiennych stanowią jeden z podstawowych elementów wieloaspektowej analizy prezentowanych tu materiałów późnomezolitycznych ${ }^{21}$.

Owa, pisana w myśl programu New Archaeology, wieloaspektowa analiza uwzględniała wszelkie możliwe metody pozyskania informacji o stanowisku i źródłach archeologicznych. Warto zauważyć, że obok analizy traseologicznej zastosowano również ważną i znana, choć słabo zaznaczoną w polskiej literaturze, metodę składanek ${ }^{22}$.

W końcu lat siedemdziesiątych i początkach osiemdziesiątych odbyła sięjedyna ożywiona dyskusja, dotycząca traseologii, jej możliwości poznawczych i ograniczeń oraz zagadnień metodycznych ${ }^{23}$. W toku tej dyskusji pojawiła się ważna refleksja:

Od opublikowania podstaw traseologii (Siemionow 1957) mija właśnie 20 lat. W ciagu tego okresu badania funkcji narzędzi poprzez analizy mikroskopowe i weryfikujące je eksperymenty niezwykle się rozwinęły. W wielu krajach (np. w ZSRR, USA, NRD) powstały wyspecjalizowane instytuty. Fachowa literatura $\mathrm{z}$ roku na rok gwałtownie się powiększa. [...] W Polsce zaś badania tego typu prowadzone są w sposób amatorski i w minimalnym zakresie. Zarówno nasi oponenci, jak i my zajmujemy się traseologią w sposób dorywczy, brak nam więc koniecznego przy takich pracach doświadczenia. Taki stan rzeczy nie rokuje nadziei na przyszłość. Najwyższy już chyba czas, aby archeologia polska doczekała się pracowni traseologicznej z prawdziwego zdarzenia ${ }^{24}$.

\footnotetext{
${ }^{19} \mathrm{Małecka-Kukawka} 2001$, s. 18-19.

${ }^{20} \mathrm{Lech} 1999$, s. 117-119.

${ }^{21}$ Schild, Marczak, Królik 1975, s. 32.

${ }^{22}$ Tomaszewski 1986 , s. 239-277.

${ }^{23}$ Szerzej Małecka-Kukawka 2001, s. 19

${ }^{24} \mathrm{~B}$ ą bel, Budziszew sk i 1978, s. 145.
} 
Bez wątpienia zasługą procesualnego kierunku badawczego było intensywniejsze zainteresowanie studiami nad funkcjami narzędzi. Jednak, pomijając kilka prac, w których pojawiły się elementy analizy mikroskopowej (zwykle sprowadzone do krótkich informacji o zadokumentowanych śladach zużycia, rysunków narzędzi i, rzadziej mikrofotografii $^{25}$ ), nie doszło do upowszechnienia wiedzy, wynikającej z analizy funkcjonalnej, nie stała się też ona standardem opracowań krzemieniarskich.

Na pewno osiagnięciem środowiska archeologów, wiążących swe zainteresowania badawcze z nurtem procesualnym, jest stworzenie możliwości wykształcenia archeologa-,,traseologa”, M. Winiarskiej-Kabacińskiej, która napisała pierwszą w dziejach polskiej archeologii dysertację doktorską z zakresu analizy funkcjonalnej w 1996 r.

\section{INSPIRACJE Z KRGU TEORII MATERIALIZMU HISTORYCZNEGO}

Pozostając przy latach siedemdziesiątych i osiemdziesiątych, trzeba odnotować zainteresowania analizą funkcji narzędzi neolitycznych $\mathrm{B}$. Balcera ${ }^{2 \mathrm{t}}$. Był on czynnym uczestnikiem wspomnianej wyżej dyskusji ${ }^{27}$. Zamieszczoną w jednym z jego artykułów myśl, można by potraktować jako wytyczenie nowego kierunku badań:

Archeolodzy już od dawna zdają sobie sprawę, że jednym z najważnicjszych zagadnień badawczych prahistorii jest właściwa klasyfikacja funkcjonalna znajdowanych narzędzi pracy, która rzutuje bezpośrednio na rekonstrukcję gospodarki dawnych społeczeństw ${ }^{2 R}$.

Jednak najważniejsze prace, w których B. Balcer sporo miejsca poświęcił badaniom funkcji, to Krzemień świeciechowski z 1975 r. i Wytwórczość narzędzi krzemiennych z $1983 \mathrm{r}$. W tej późniejszej pracy, w której inspiracje wypływające z języka materializmu historycznego są bardziej wyraźne, autor stwierdza, że: „krzemieniarstwo można uznać za jeden z głównych elementów bazy związanej z produkcją środków produkcji [a także] produkcja narzędzi krzemiennych była niewątpliwie czynnikiem gospodarczego rozwoju społeczności neolitycznych" ${ }^{29}$.

W świetle tej deklaracji, zastosowanie traseologii do badań narzędzi żniwnych (sierpaków) kultury pucharów lejkowatych, które - jako „wytwory poprzełomowe” miały być bardziej wydajne niż narzędzia wcześniejszych kultur wstęgowych, wydaje się zrozumiałe, choć autor, świadom własnego ,półamatorskiego" warsztatu traseologicznego, ograniczył się do analizy jednej kategorii narzędzi ${ }^{30}$.

\footnotetext{
${ }^{25}$ Np. Pianowski 1978; Drobniewicz 1978 i 1979; Balcer, Schild 1980; Grygiel 1986; Cyrek 1986: Burdukiewicz 1987.

${ }^{26} \mathrm{~B}$ a lcer $1975 ; 1983$.

${ }^{27}$ Np. Balcer, Schild 1978a; 1978b; 1980.

${ }^{28}$ Balcer, Schild 1978a, s. 44.

${ }^{29} \mathrm{~B}$ a l cer 1983 , s. 15.

${ }^{30} \mathrm{~B}$ alcer 1983 , s. 36.
} 


\section{PRÓBA PODSUMOWANIA}

W dominującym w studiach nad epoką kamienia nurcie kulturowo-historycznym nie było miejsca na pogłębione badania z zakresu szeroko rozumianej funkcji narzędzi. Najnowsze syntezy ${ }^{31}$ w częściach dotyczących epoki kamienia w niewielkim stopniu różnią się od syntez sprzed lat. Traseologia wprawdzie jest wzmiankowana, jednak sama informacja o metodzie, bez pokazania przykładów jej zastosowań i możliwości interpretacyjnych nic nie wnosi do wiedzy o pradziejach.

Sądzę więc, że kulturowo-historyczny model uprawiania archeologii stał się głównym hamulcem rozwoju traseologii w Polsce. Wprawdzie sama metoda, z racji rozwoju poza Polską znalazła swe miejsce w podrecznikach ${ }^{32}$, ale wyniki opracowań traseologicznych zwykle są aneksami do „klasycznych” opracowań archeologicznych, na równi $z$ innymi, aneksowymi opracowaniami z zakresu na przykład nauk przyrodnicznych czy antropologicznych. Dane z aneksów rzadko są „konsumowane” przez archeologów.

Procesualny epizod $z$ traseologią także nie przełożył się na trwałe upowszechnienie wiedzy, wynikającej ze znajomości funkcji narzędzi, choć niewątpliwie za sprawą ,procesualistów" powstał pierwszy doktorat z tego zakresu, a M. Winiarska-Kabacińska sukcesywnie publikuje wyniki swoich badań.

Trudno też - poza odnotowaniem prób analizy funkcjonalnej - w pracach B. Balce$\mathrm{ra}^{33}$ oceniać jego wkład w rozwój tej metody. Analizy traseologiczne tylko jednej, szczególnej kategorii narzędzi (z widocznym makroskopowo wyświeceniem) utwierdziły go w przekonaniu, że wszystkie ,sierpaki” są narzędziami do ścinania zbóż ${ }^{34}$. W swej ostatniej pracy B. Balcer trafnie ujął podejście archeologów „krzemieniarzy” co do potrzeb i przydatności wykonywania analiz traseologicznych, i które - uważam - stanowić może odpowiedź na postawione we wstępie pytanic o przyczyny słabej recepcji traseologii:

Do narzędzi zaliczone zostały wytwory ze śladami obróbki i użytkowania widocznymi bez zastosowania mikroskopu. Do śladów tych należy retusz krawędzi i wierzchołków oraz wygładzenie i wyświecenie powierzchni narzędzi. Obydwa rodzaje śladów mogły powstać zarówno w wyniku celowej obróbki półsurowca i półwytworów przystosowywanych do roli narzędzi pracy, jak i wykruszenia, zagładzenia i wyświecenia nieobrobionych półsurowiaków użytkowanych bez obróbki przygotowawczej. [...] G.F. Korobkowa, kontynuatorka badań S.A. Siemionowa, powtarza od lat, że jak to wynika z badań traseologicznych, odłupki, wióry i okruchy krzemienia mogły być użytkowane jako narzędzia bez dodatkowej obróbki. [...] w przypadku materiałów z Gawrońca wymagałoby mikroskopowego przebadania, o ile nie wszystkich wytworów krzemiennych, to przynajmniej kilku tysięcy okazów w postaci wiórów, odłupków, okruchów i półwytworów narzędzi rdzeniowych. Można to wysunąć jako postulat badawczy na przyszłość, a obecnie do narzędzi zaliczono okazy na podstawie ich oględzin bez zastosowania przyrządów optycznych [podkr. J. M.-K. $]^{35}$.

\footnotetext{
${ }^{31}$ Np. Kaczanowski, Kozłowski 1998; Kozłowski 1999

${ }^{32} \mathrm{~Np}$. Ginter, Kozłowski 1990.

${ }^{33}$ Balcer 1975; 1983 .

${ }^{34} \mathrm{~B}$ a l c e r 2002 , s. $77-78$

${ }^{35}$ B alcer 2002, s. 66.
} 
Nic dodać, nic ująć, morfologia, techniki, surowce, typologia. Badania funkcji nadal - jak przez ostatnich kilka dziesięcioleci - jako postulat badawczy na przyszłośćc ${ }^{36}$.

Nie można jednak nie odnotować faktu, że w wielu programach badawczych, inicjowanych przez polskich badaczy (już bez względu na przyjmowaną orientację teoretyczną) analizy traseologiczne są wykonywane, ale przez zapraszanych do współpracy specjalistów zagranicznych ${ }^{37}$. Oznacza to więc, że przydatność analizy funkcjonalnej jest dość powszechnie doceniana. Dlaczego jednak w Polsce nie rozwinęła się traseologia? Być może odpowiedzi należy poszukiwać nie w orientacjach teoretycznych, a w zupelnie innym, pozanaukowym wymiarze?

\section{UKRYTY CZYNNIK LUDZKI}

Na zakończenie chciałabym zawrzeć kilka osobistych refleksji, związanych z poruszoną wyżej problematyką. Nie ulega wătpliwości, że zastosowanie danej metody analitycznej zawsze jest podporządkowane stawianym celom badawczym. Nie ma metod lepszych i gorszych, żadna z metod sama w sobie nie interpretuje źródeł. To archeolog, stosując wybrane według własnego kwestionariusza pytań procedury analityczne, komentuje ich wyniki i interpretuje przeszłą rzeczywistość.

Nie jest jednak do końca prawdą, że słaby rozwój traseologii w Polsce wynika tylko z dominacji nurtu kulturowo-historycznego, w którym znajomość funkcji narzędzi jest owszem - interesująca, ale nie niezbędna. Otóż traseologia jest metodą niewdzięczną. Wymaga wielkich nakładów czasu, pracy i cierpliwości. Funkcje narzędzi określa się długo i żmudnie, a wyniki sq̨ mało romantyczne, o czym wielokrotnie wspominali cytowani autorzy. Procedury czyszczenia jeszcze ten czas wydłużają. Nie można poprawnie wykonywać analiz traseologicznych bez zaplecza licznych wzorców eksperymentalnych. Wykonanie eksperymentów także pochłania mnóstwo czasu. Dokumentację, zwłaszcza fotograficzną, wykonuje się długo i mozolnie. Uzbieranie wartościowego materiału, który mógłby stanowić podstawę źródłową do uzyskania stopnia naukowego z zakresu traseologii, w zasadzie jest możliwe. W zasadzie, zaledwie bowiem jedna praca doktorska M. Winiarskiej-Kabacińskiej z 1996 r. i moja praca habilitacyjna z 2001 r. na ponad czterdzieści lat znajomości traseologii w polskiej archeologii mogą uświadamiać skalę trudności, jaką musi pokonać potencjalny ,traseolog”. Przygotowanie książki Między forma a funkcja zajęło mi kilkanaście lat, a było możliwe tylko dzięki współpracy ze środowiskiem petersburskich traseologów, dostępem do ogromnej kolekcji materialów eksperymentalnych i - przede wszystkim - możliwością dyskusji. W Polsce takiego środowiska nie było. Cóż, typologię ,robi się” dużo łatwiej i szybciej...

\footnotetext{
${ }^{36}$ Dobrą ilustracją do refleksji nad zainteresowaniem (czy raczej nad jego brakiem) traseologia jest zakres problematyki badań nad epoką kamienia, przedstawiony w kilku podsumowujących artykułach w pracy Archeologia i prahistoria polska w ostatnim pólwieczu, red. Kobus i ew i c z, K u r nat ow sk i, 2000.

${ }^{37}$ Np. Schild, Wendorf 1976; Caspar, Kaczanowska, Kozłowski 1989; Ginter, Kozłowski, Laville 1994; Willis 1990; 1993.
} 


\section{BIBLIOGRAFIA}

\section{A. Skróty}

AP - Archeologia Polski, Warszawa;

PMMAE - Prace i Materiały Muzeum Archeologicznego i Etnograficznego w Łodzi, Łódź; SA - Sprawozdania Archeologiczne, Kraków;

ZOW - „Z otchłani wieków”, Warszawa.

B. Literatura

Abramowicz A.

1991 Historia archeologii polskiej XIX i XX wiek, Warszawa-Łódź.

Balcer B.

1975 Krzemień świeciechowski w kulturze pucharów lejkowatych. Eksploatacja, obróbka i rozprzestrzenienie [Sum.: The Świeciechów flint in the Funnel Beaker Culture. Exploitation, working and distribution], Wrocław-Warszawa-Kraków-Gdańsk.

1983 Wytwórczość narzędzi krzemiennych w neolicie ziem polskich [Zus.: Die Herstellung von Feuersteingeräten im Neolithikum auf dem Gebiet Polens], Wrocław-Warszawa-Kraków-Gdańsk-Łódź.

2002 Ćmielów-Krzemionki-Świeciechów. Zwiqzki osady neolitycznej z kopalniami krzemienia [Sum.: Ćmielów-Krzemionki-Świeciechów. Relations between the neolithic settlement and flint mines], Warszawa.

Balcer B., Schild R.

1978a A jednak sierpy!, ZOW r. 44, nr 1, s. 44-48.

1978b Sierpem i gtowę można uciać..., ZOW r. 44, nr 2, s 145-147.

1980 Traces of Wear and StoneTool Function: Do They Really Mean What They Show?, Unconventional Archaeology. New Approaches and Goals in Polish Archaeology, Wrocław-Warszawa-Kraków-Gdańsk, s. 109-116.

Barford P.

1995 Marksizm $w$ archeologii polskiej w latach 1945-1975, AP t. 40, z. 1-2, s. 7-78.

Bąbel J., Budziszewski J.

1978 Noze wielofunkcyjne! ZOW r. 44, nr 2, s. 139-145.

Burdukiew ic z J.M.

1987 Późnoplejstoceńskie zespoly z jednozadziorcami w Europie Zachodniej [Zus.: Spătpleistozöne Kerbspitzen-Gruppen in Westeuropa], Acta Universitatis Wratislaviensis, Studia Archeologiczne XIV, Wroclaw.

Caspar J.-P., Kaczanowska M., Kozłowski J.K.

1989 Chipped stone industries of the Linear Band Pottery Culture (LBP), techniques, morphology and function of the implements in Belgian and Polisch assemblages, „Hellinium” 29, s. 157-205.

Cook J., Dumont J.

1987 The development and application of microwear analysis since 1964, (w:) G. de G. Sieveking, M. H. Newcomer (ed.), The human uses flint and chert. Proceedings of the Fourth International Symposium held at Brighton Polytechnik, 10-15 April 1983, CUP, Cambridge, s. 53-61.

Cyrek K.

1986 Późnopaleolityczne stanowisko w Kochlewie, województwo sieradzkie [Sum.: A late paleolithic camp and a flint workshops at Kochlew, province of Sieradz], PMMAE t. 30, s. 5-79. 
Drobniewicz B.

1978 Analiza mikroskopowa zabytków z grobu kultury lendzielskiej (nr 1325) na stanowisku 17 w Pleszowie (Kraków-Nowa Huta) [Sum.: The microscopic analysis of finds from a Lengyel grave (no 1325 ) on site 17 at Pleszów (Kraków-Nowa Huta)], SA t. 30, s. 31-33.

1979 Analiza traseologiczna wyrobów krzemiennych z cmentarzyska kultury ceramiki sznurowej w Koniuszy, woj. Krakow [Sum.: The traseological analysis of flint artifacts frm the cemetery of the corded ware culture at Koniusza, province of Kraków], SA t. 31, s. 91-94.

Ginter B., Kozłowski J.K.

1990 Technika obróbki i typologia wyrobów kamiennych paleolitu, mezolitu i neolitu, Warszawa.

Ginter B., Kozłowski J.K., Laville H. (eds.)

1994 Temnata Cave. Excavations in Karlukovo Kars Area, vol. 1, part 2, Kraków.

Grygiel R.

1986 The household cluster as a fundamental social unit of the Lengyel Culture in the Polish Lowlands, PMMAE t. 31, s. 43-270.

Ha y den B. (ed.)

1979 Lithic Use-Wear Analysis, Academic Press, New York-San Francisco-London.

J e n s e n H.J.

1988 Functional analysis of Prehistoric Flint Tools by High-Power Microscopy. A Review of West European Research, „Journal of World Prehistory” vol. 2, no. 1, s. 53-88.

Kaczanowski P., Kozłowski J.K.

1998 Wielka historia Polski, t. I: Najdawniejsze dzieje ziem polskich, Kraków.

Kobusiewicz M., Kurnatowski S. (red.)

2000 Archeologia i prahistoria polska w ostatnim pólwieczu, Poznań.

Korobkowa G.F.

1999 Narzędzia $w$ pradziejach. Podstawy badania funkcji metodq traseologicznq, Torun.

Korobkova G.F., Šc̆elinskij W.E.

1996 Metodika mikro-makroanaliza drevnich orudij truda, cz. 1, St. Petersburg.

Kozłowski J.K.

1971 Uwagi o znaczeniu i metodach badań nad neolitycznymi inwentarzami krzemiennymi, (w:) $Z$ badań nad krzemieniarstwem neolitycznym i eneolitycznym, red. J.K. Kozłowski, Kraków, s. 139-146.

1999 Encyklopedia historyczna świata, t. 1: Prehistoria, Kraków.

Kozlowski S.K.

1968 Ciach go drapaczem, ZOW r. 34, nr 1, s. 90-92.

Lec h J.

1997 Malowierni. Spór wokót marksizmu w archeologii polskiej lat 1945-1975 [Sum.: Current controversy over Marxism in Polish archaeology in the years 1945-1975], AP t. 47, z. 1-2, s. 175-232.

1999 Between Captivity and Freedom. Polish Archaeology in the 20 th Century, Warszawa.

2000 Kultura archeologiczna: $z$ dziejów jednego pojęcia [Sum.: Archaeological culture: the history of one concept], (w:) Kultury archeologiczne a rzeczywistość dziejowa, red. S. Tabaczyński, Warszawa, s. $151-183$

Malecka-Kukawka J.

2001 Między formq a funkcja. Traseologia neolitycznych zabytków krzemiennych z ziemi chelminskiej [Sum.: Between Form and Function. Traseological Analysis of the Neolithic Flint Assemblages from Chełmno Land], Torun.

$\mathrm{Mamzer} \mathrm{H}$.

2004 Archeologia $i$ dyskurs. Rozważania metaarcheologiczne [Sum.: Archaeology and Discourse. Metaarchaeological Considerations], Poznań.

Pianowski Z.

1978 Analiza traseologiczna wyrobów krzemiennych ze stanowiska schylkowopaleolitycznego Wapiennik 1/64, woj. Częstochowa [Sum.: The Traseological Analysis of Flint Artifacts 
from the Late Paleolithic Site Wapiennik I/64, Province of Częstochowa], SA t. 29, s. $205-220$.

$\mathrm{S}$ i e menov S.A.

1957 Pervobytnaja technika. Opyt izučenija drevnejsich orudij po sledam roboty, Materialy i Issledovanija po Archeologii SSSR. Moskwa-Leningrad.

1964 Prehistoric technology, London.

Schild R., Marczak M., Królik H.

1975 Późny mezolit. Próba wieloaspektowej analizy otwartych stanowisk piaskowych [Sum.: The Late Mesolithic. An example of multiaspectual analysis of open air sites from sandy lowlands], Wrocław-Warszawa-Kraków-Gdańsk.

Schild R., Wend orf F.

1976 Wear Pattern of some Artifacts from Isnana Sities, (w:) Prehistory of the Nile Valley, ed. R. Schild, F. Wendorf, San Francisco-London-New York.

Tom aszews k i A.J.

1986 Metoda skladanek wytworów krzemiennych i jej walory poznawcze [Sum.: Style and chipped stone artefacts - a Review of some problems], AP t. 31, z. 2, s. 239-277.

1988 Wytwory kamienne i styl - przeglad problematyki [Sum.: The method of refittings of chipped stone artefacts and its research value], AP t. 33, z. 1, s. 7-59.

Unrath G., Owen L.R., van Gijn A.L., Moss E.H., Plisson H., Vaughan P.

1986 An evaluation of use-wear studies. A multi-analyst approach, (w:) Technical aspects of microwear studies on stone tools, eds. L.R. Owen, Unrath G., Early Man News 9/10/11, part 1, Tübingen.

W ill is $R$.

1990 Dęby 29 - the Functional Analysis of a Late Mesolithic Site in Poland and its Significance in the Polish Context, (w:) Contributions to the Mesolithic in Europe, eds. P.M. Vermeersch, P. van Peer, Leuven University Press, s. 295-297.

1993 The Site of Deby 29 and the Transition to Farming in the North European Plain, ,Mesolithic Miscellany" vol. 13, nr 2, s. 18-26.

Win i a r sk a - K a b a cińs k a $\mathrm{M}$.

1996 Gospodarka spoteczności mlodszego driasu na Niżu Polskim w'świetle analizy funkcjonalnej materialów krzemiennych (maszynopis rozprawy doktorskiej).

\section{ON HISTORY OF TRASEOLOGY IN THE POLISH STONE AGE ARCHAEOLOGY}

\section{Summary}

A book Piervobytnaja technika by S.A. Se menov was published almost a half a century ago (1957; English edition entitled Prehistoric technology appeared in 1964). This is a sufficient perspective to look at development of traseology in Polish archaeology, in particular to understand reasons of a lack of interest in functional analysis as compared to significance inscribed to typology and raw material studies in Stone Age archaeology.

I would argue that a lack of interest in functional analysis, since the time its methodological foundations were published, is caused by particular research objectives of prehistory, known as culture-historical archaeo$\operatorname{logy}$, and formed in the milieu of Polish archaeologists of the 1920s. A dominance of 'archaeological culture' as a research tool and subject of studies in the Polish post-war archaeology resulted in rejection of a microscopic method of functional analysis in Stone Age studies.

Considering political context of the post-war archaeology, one would expect that this new method referring directly to work tools, a material category aimed at studying forces of production, could and should be enthusiastically welcomed. However, a reception of historical materialism among Polish prehistorians was weak. Marxist inspirations were clearly seen in works by B. Balcer (1975 and in particular 1983). Accordingly, it was 
him who applied elements of traseology in the studies of one category of tools, namely harvest implements. However, as he stated himself, traseology lacked a solid methodological foundation.

A revival of interests in traseology in Polish archaeology is dated back to the 1970s of the bygone millennium. It was due to rejection of a culture-historical model of practising archaeology and focusing of research interests on social, economic and ecological processes by a group of archaeologists of that period (processualism; Le ch 1999, s. 117-119). The turn of the 1970s brought about the only vivid discussion on traseology, its heuristic potential and limitations, methodological issues, etc. (Bąbel, Budziszewski 1978; Balcer, Schild 1978a, 1978b, 1980).

This processual episode, however, has not resulted in a permanent application of traseology as a means of studying function of prehistoric tools. One needs to note, however, that these processual interests has resulted in preparation of the only one Ph.D. dissertation in the field to date (M. W i n i a s $\mathrm{k}$ a - K a b a c i n s k a 1996).

However, this unsatisfactory development of traseology in Poland is not caused by a dominance of culture-historical paradigm only, in which recognition of tool function is interesting, albeit not indispensable. It is also determined by a human factor. Traseology is an unrewarded method requiring a large amount of time, effort, and patience. A scale of difficulty to be overcome by a potential 'traseologist' is proven by only two dissertations in the field in Polish archaeology written over the last forty years, namely a Ph.D. thesis by M. Winiarska-Kabacińska (1996) and a Habilitation dissertation by J. Małecka-Kukawka (2001). 